\title{
Prevalence of Caesarean Section in Matri Shishu Miteri Hospital of Gandaki Province
}

\section{Prem Raj Pageni ${ }^{1}$, Rajesh Adhikari ${ }^{1}$, Padma Raj Dhungana ${ }^{1}$, Deepak Raj Kafle ${ }^{1}$}

${ }^{1}$ Department of Obstetrics and Gynaecology, Pokhara Academy of Health Sciences

\section{Correspondance:}

Dr. Prem Raj Pageni, MD

Department of Obstetrics and Gynecology

Pokhara Academy of Health Sciences,

Western Regional Hospital,Pokhara, Nepal

Email: prpageni@gmail.com

Article received: Oct 162019

Article accepted: March 192020

\section{ABSTRACT}

Background : Caesarean section (CS) is one of the commonest obstetrics procedure to reduce the risks for mother and fetus when vaginal delivery is not anticipated . The objective of the study was to determine the rate and clinical indication of Caesarean section.

Materials and Methods: This was a hospital based descriptive retrospective study done within a time frame of a year (from Shrawan 2075 BS to Ashad 2076 BS; 17 July 2018 to July 16 2019) in Matri Shishu Miteri Hospital, Pokhara,Nepal. The total number of deliveries, their modes of delivery, indication for the Cesarean section, age group, number of parity, period of gestation and type of Caesarean section either elective or emergency were descriptively analyzed.

Results: A total of five hundred and eighty eight cases underwent delivery during the study period. Of them $128(21.76 \%)$ cases were delivered by Caesarean section. Analysis revealed that the common age group for the CS patients was between 20-30 years (64.8\%) of them $66(51.6 \%)$ cases were primi gravida. Emergency Caesarean section was done for 75(58.6\%) cases and elective Caesarean section for 53(41.4\%) cases. The most common indication for Caesarean section was found to be previous caesarean section $21 \%(n=27)$, cephalopelvic disproportion (CPD) $18 \%(\mathrm{n}=23)$, fetal distress $18 \%(\mathrm{n}=23)$, failed induction $14.1 \%(\mathrm{n}=18)$, breech presentation $10.2 \%(\mathrm{n}=13)$, non progress of labor (NPOL) $9.4 \%(\mathrm{n}=12)$ and oligohydramnios $7.8 \%(n=10)$.

Conclusion: Our study revealed that the rate of Caesarean section is higher than that recommended by World Health Organization (WHO), which needed to be $10-15 \%$ of the total deliveries. The common indications for Caesarean sections were pervious Caesarean section, fetal distress, CPD, failed induction, breech presentation, non progress of labour (NPOL) and oligohydramnios among others.

KeyWords:Caesarean Section, Failed Induction, 
Original Article

Introduction

Caesarean Section (CS) is one of the commonly done operative procedures in obstetrics. Caesarian section rate(CSR)has been a public health concern since last few years.In 1985 WHO recommended an optimal CS rate of $10-15 \% .{ }^{1}$ The rate of CS is rising in recent years. Increase in CSR has been attributed to factors such as previous caesarean section, fetal distress, advanced maternal age at delivery, socioeconomic factors or change in clinical management of labor. ${ }^{2}$ Although CSR in many centers have increased above the recommended level in both developed and many developing countries, the rate of delivery through caesarean section is relatively low in Nepal. ${ }^{3}$ The present study was conducted to find out rate and indications of CS at Matri Shishu Miteri Hospital(MSMH), a government maternity center in western part of Nepal.

\section{Materials and Methodology}

A hospital based retrospective descriptive study was conducted at MSMH, Batulechour-16, Pokhara, Kaski, Gandaki province of Nepal. All the cases who underwent CS and vaginal delivery between $1^{\text {st }}$ Shrawan 2075 and $31^{\text {st }}$ of Asar $2076\left(17^{\text {th }}\right.$ July 2018 to $16^{\text {th }}$ July 2019$)$ were included in the study.

Ethical approval for the study was obtained from the hospital administrative office. CS data, normal delivery and instrumental delivery data were collected from medical record section of the hospital. Data were verified by reviewing registers kept in labor room. Elective CS was defined as a CS performed without emergency indication and decision of operation made before the onset of labor. Emergency CS was defined as those performed for emergency feto- maternal reasons. Clinical indications were noted for both elective and emergency CS. The period of gestation at the time of presentation, gravida, types of caesarean section, indications of Caesarean section, parity and obstetric background were noted. The data was entered and analyzed using SPSS 20 version. The CSR was calculated as the number of CS per 100 deliveries.

\section{Results}

Total number of deliveries during that period was
Medical Journal of Pokhara Academy of Health Sciences Vol. 3 Issue 1 588.Total CS were 128 that occupies $21.76 \%$ of all the deliveries. Following table revealed the mode and percentage of deliveries during that period

Table 1: Type and percentage of delivery

\begin{tabular}{|l|c|c|}
\hline Type of delivery & No. of patients & Percentage \\
\hline Normal delivery & 436 & $74.14 \%$ \\
\hline Instrumental Delivery & 24 & $4.08 \%$ \\
\hline Caesarean Section & 128 & $21.76 \%$ \\
\hline
\end{tabular}

Most of the patients delivered by CS method were between the age group of 20-30 years (64.8\%) followed by age group between $30-40$ years $(28.1 \%)$. Maternal age less than 20 years who had CS stands only $7 \%$.(

Figure 1)

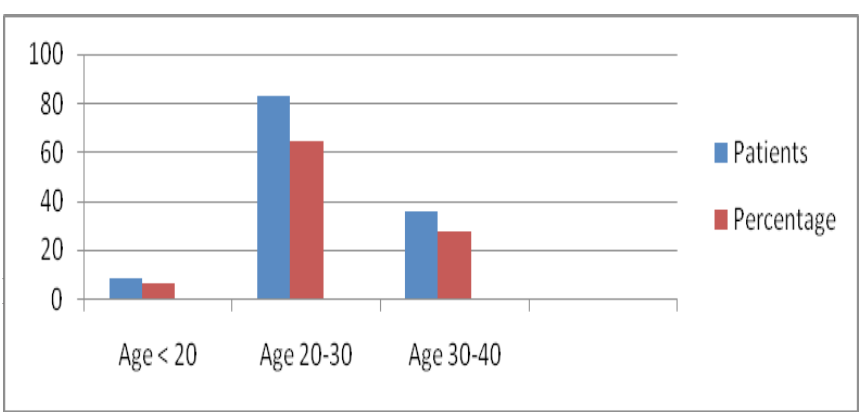

Besides the study also revealed that Primi gravida who went Caesarean section were 51.6\% $(\mathrm{n}=66)$ and Multigravida who went caesarean section were $48.4 \%($ $\mathrm{n}=62$ ). (Figure 2)

\section{Figure 2: Parity Distribution and CS rate}

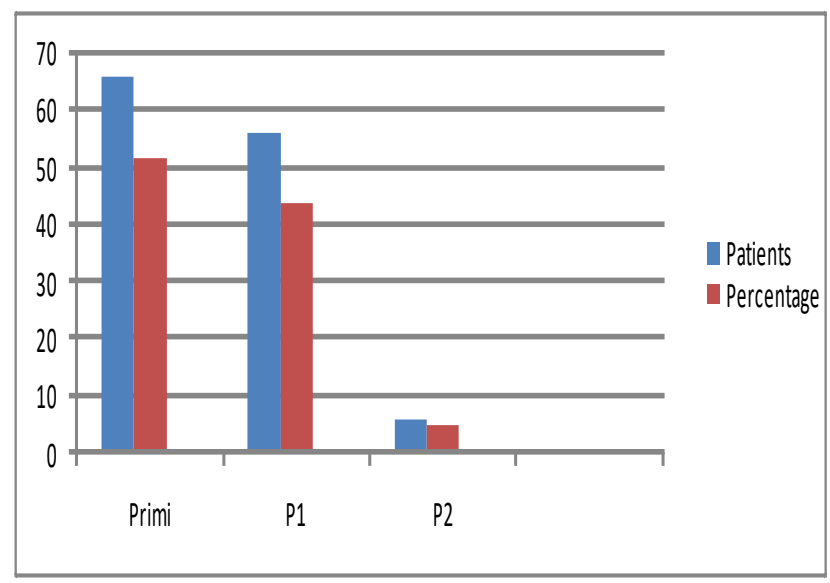

Similarly the total patients that underwent caesarean section at period of gestation 37-40 weeks were $29.7 \%(n=38)$.Patient underwent caesarean section at period of gestationafter 40 weeks were $70.3 \%(n=90)($ 
Table 2)

Table 2:Rate of CS according to period of gestation

\begin{tabular}{|l|c|c|}
\hline Period of Gestation & $\begin{array}{c}\text { No. of patients } \\
(\mathrm{n}=128)\end{array}$ & Percentage \\
\hline$<40$ weeks & 38 & $29.7 \%$ \\
\hline$>40$ weeks & 90 & $70.3 \%$ \\
\hline
\end{tabular}

Out of 128 CS, 75 patients underwent for emergency CS whereas 53 patients underwent for elective CS ( Table 3)

Table 3:Percentage of elective and emergency CS

\begin{tabular}{|l|c|c|}
\hline \multicolumn{1}{|c|}{$\begin{array}{c}\text { Categories of caesarean } \\
\text { section }\end{array}$} & $\begin{array}{c}\text { No. of patients } \\
(\mathrm{n}=128)\end{array}$ & Percentage \\
\hline $\begin{array}{l}\text { Elective caesarean } \\
\text { section }\end{array}$ & 53 & $41.4 \%$ \\
\hline $\begin{array}{l}\text { Emergency caesarean } \\
\text { section }\end{array}$ & 75 & $58.6 \%$ \\
\hline
\end{tabular}

The most common indication and distribution of various indications of Caesarean section are listed as in table 4.Common indications included fetal distress, CPD, failed induction, NPOL, breech and oligohydromnios.

Table 4:Indication of CS with their percentage.

\begin{tabular}{|l|c|c|}
\hline Indication & $\begin{array}{c}\text { No. of patients } \\
(\mathbf{n}=128)\end{array}$ & Percentage \\
\hline Previous LSCS & 27 & $21.1 \%$ \\
\hline Fetal Distress & 23 & $18 \%$ \\
\hline CPD & 23 & $18 \%$ \\
\hline Failed Induction & 18 & $14.1 \%$ \\
\hline Breech & 13 & $9.4 \%$ \\
\hline NPOL & 12 & $9.3 \%$ \\
\hline Oligohydromnios & 10 & $7.8 \%$ \\
\hline Others & 2 & $1.6 \%$ \\
\hline Total & 128 & $100 \%$ \\
\hline
\end{tabular}

\section{Discussion}

There is an increasing rate of CS not only in Nepal but all over the world, which is an area of major concern. Factors associated with high CS rate may be due to fear of litigation, CS by choice of the patient, increased use of electronic monitoring of fetus, increased proportion of breech deliveries by CS and deliveries in private set up. ${ }^{4}$ Our CSR was $21.75 \% \quad(n=588)$. The most common reasons for performing $\mathrm{CS}$ were previous CS, fetal distress and CPD. Similar study done at a community hospital of western region of Nepal found CS rate as $63.27 \%$, which was quite high as compared to our study. ${ }^{5}$ The rate of CS at our hospital was also slightly higher than other district level hospitals or Comprehensive Emergency Obstetric and Neonatal Care(CEONC) center. This may be because our hospital is located in Pokhara, which is among of major cities in Nepal. Few referral cases from other nearby district hospitals also visit our centre for CS. The most common indication for CS in community hospital in Pokhara is oligohydromnos, 23.56\%. ${ }^{5}$ However our study revealed that the most common indication in our centre was previous caesarean section which was similar to the study done in Kathmandu Medical College (KMC) by Apurwa Prasad et al. ${ }^{6}$

Current medical literature suggests that $60-80 \%$ of women can achieve vaginal delivery. ${ }^{7}$ Sharma et al. in their studies found indication of repeat elective caesarean section was refusal of trial of scar, when the women were told about risk associated with trial of scar like uterine rupture, scar dehiscence and bleeding due to adherent placenta. ${ }^{7}$ Repeat caesarean section is much safer and convenient for an obstetrician and less likely to give rise to other complications of scar dehiscence and possible subsequent litigation and maternal preference. ${ }^{6}$ It is seen that repeat CS is doctor friendly than Vaginal Birth After Caesarean (VBAC).

The rate of CS is not same in all parts of Nepal. A study showed that Caesarean section rate is significantly high in urban areas than in rural areas of Nepal. ${ }^{8}$ Overall CS rate in Nepal was 9\% in 2016 (7.1\% in rural as compared to $19 \%$ in urban). ${ }^{9}$

A study done by Rai, Sulachana Dhakal et al. in 2016 found that the caesarean section rate was highest in Kirtipur Hospital 50.9\%, Kathmandu Medical College hospital 48.81\%, Patan Hospital 41.9\%, BP Koirala Institute of Health Sciences (BPKIHS) 28.6\%, Tribhuwan University Teaching Hospital (TUTH) 25.41\%, Mid Western Regional hospital $18.9 \%$, Okhaldhunga Community Hospital 9.5\% ${ }^{8}$. Our study showed that caesarean section rate of $21.76 \%$ in MSMH during that time frame. 


\section{Original Article}

The second common indication for Caesarean section was fetal distress and CPD in our centre accounting 18\% which was similar to the study done by Apurwa Prasad et al. She found CS rate for fetal distress was 19.55\%.

Similarly, the third common indication for Caesarean section was failed induction accounting 14.1\% which was lower than study done in KMC by Apurwa Prasad et al $(19.73 \%)^{6}$

The fourth common reason for Caesarean section was breech presentation resulting $10.2 \%$. A study done in $\mathrm{KMC}$, percentage of Caesarean section due to breech was $8.5 \% .{ }^{6}$ For breech presentation, both emergency and elective Caesarean sections were done. MSMH adopted the policy to have planned caesarean section for all breech until and unless they come late in labor. A metaanalysis done by Hannah et al. showed significantly low rate of perinatal morbidity and mortality with planned Caesarean section than with planned vaginal birth in cases of breech presentation. ${ }^{10}$

Similarly our study revealed that the incidence for Caesarean section due to non-progress of labor is $9.4 \%$ which was higher than study done at $\operatorname{KMC}(0.7 \%){ }^{6}$

Oligohydroamnios was the most common indication for CS in community hospital in Pokhara ${ }^{5}$ standing $23.56 \%$ which was quite different in our study standing only $7.8 \%$ while the other study in different part of Nepal revealed only $2.2 \%{ }^{6}$

Our study revealed that elective Caesarean section rate was $41.4 \%$, emergency caesarean section was $58.6 \%$; whereas a study done in KMC showed elective Caesarean section of $23.4 \%$, emergency caesarean section was $76.5 \%$ reason behind may be due to higher patient flow in $\mathrm{KMC}$ which is a tertiary referral center.

\section{Conclusion}

The rate of Caesarean section in MSMH is higher than that recommended by WHO, Standard rate should be $10-15 \%$ of the total deliveries. The emergency Caesarean section was higher than elective caesarean section. The common indications for Caesarean section were pervious Caesarean section, fetal distress, CPD, failed induction, breech presentation, non- progress
Medical Journal of Pokhara Academy of Health Sciences Vol. 3 Issue 1 of labor,oligohydramnios and others.This study suggests that primary CS should not be encouraged as far as possible to reduce the possibility of repeat CS in subsequent pregnancy to limit unwanted surgical complications.

\section{REFERENCES:}

1. World Health Organization. WHO statement on caesarean section rates. Geneva:World Health Organization, 2015.

2. Cai WW, Marks JS, Chen CH,Zhuan YX, Morris L,Harris JR. Increased cesarean section and emerging pattern of health insurance in Shanghai, China. Am J Public Health.1998;88(5);777-80.

3. Saha S, Das R, Chakraborty M, Bala HS, Naskar P. A Paradigm Shift to check the increasing trend of caesarean delivery is the need to tohour:but how? Obstet Gynecol india, 2012;62(4):391-7.

4. Mukherjee SN. Rising Caesarean RateObstetGynecol India.2006;56(4):298-300.

5. Chaudhary, Rajendra etal, Prevalance and Indication of Cesarean Section in a Community Hospital of Western Region of Nepal. JNMA,2018;56(213)871-4.

6. Prasad, Apurwaetal, Profile of Caesarean Section at Kathmandu Medical College. J Nepal Health Res Counc.2017MayAug;15(36):110-13. 
7. Sharma A, Sharma U, Chaudhary

P,Acharya A,Chaudhary A,Hanspal

J. Maternal and Neonatal outcomes

in Patients with history of previous

one caesarean section. Indian Medical

Gazette.2012;145 (5):169-73.

8. Sulochana Dhakal Rai, Pramod Raj Regmi, Edwin van Teijlingen,Juliet Wood, Ganesh

Dangal, Keshar Bahadur Dhakal. Rising

Rates of Caesarean Section in Urban

Nepal. J Nepal Health Res. Counc 2018.

oct-dec;16(4):479-80.

9. Ministry of Health and Population and

New ERA,ICF International, Nepal

Demographic and Health Survey

2016.Kathmandu Ministry of Health

and Population,New ERA and ICF

International,Calverton,Maryland,2017

10. Hannah M, Hannah.W.Caesarean section or vaginal birth for breech presentation at term.BMJ.1996Jun,312:1433-4.PMCJ. 